\title{
Plasmodium knowlesi infection imported to Germany, January 2013
}

A Bart (a.bart@amc.nl)1 ${ }^{1}$ J J van Hellemond ${ }^{2}$, P J van Genderen³ ${ }^{3}$ T Van Gool ${ }^{1}$

1. Dept. Medical Microbiology, Section Parasitology, Academic Medical Center, Amsterdam, the Netherlands

2. Dept. Medical Microbiology and Infectious Diseases, Erasmus University Medical Center and Harbor Hospital, Rotterdam, the Netherlands

3. Institute for Tropical Diseases, Harbour Hospital, Rotterdam, the Netherlands

Bart A, van Hellemond JJ, van Genderen PJ, Van Gool T. Plasmodium knowlesi infection imported to Germany, January 2013. Euro Surveill. $2013 ; 18(44)$ :pii=20619. Available online: http://www.eurosurveillance.org/ViewArticle.aspx?Articleld=20619

To the editor: We read with great interest the article by Orth et al. [1] in Eurosurveillance on a recent case of imported Plasmodium knowlesi infection in Germany. This case nicely illustrates the pivotal role of microscopy on thick and thin blood films by experienced microscopists for malaria diagnosis. The statement in the discussion section that only five cases imported to Europe have been published so far, underestimates the occurrence of this infection. Two more cases imported to the Netherlands have been described previously $[2,3]$.

One case was a migrant worker from Malayan Borneo, positive in microscopy with $2 \%$ infected erythrocytes. The rapid BinaxNOW Malaria Test was positive for the pan-malarial aldolase band but negative for $P$. falciparum histidine-rich protein 2 (HRP-2). Retrospective analysis of the initial sample also showed positive results in the $P$. falciparum-specific lactate dehydrogenase (LDH) and pan-malarial LDH in the OptiMAL Rapid Malaria Test (DiaMed, Cressier, Switzerland). This patient was successfully treated with oral chloroquine for three days [2].

The other patient was a tourist who also visited Malayan Borneo and participated in a two-day jungle trek. At presentation, this case had a low parasitaemia (0.0005\%) with microscopy and negative reactions for both HRP-2 and aldolase in the BinaxNOW Malaria Test. The patient was successfully treated with malarone, a combination of atovaquone and proguanil [3]. Both cases were confirmed as $P$. knowlesi infections by molecular methods after treatment had been started.

We agree with Orth et al that physicians should be aware of the possibility of imported $P$. knowlesi infections in travellers. This is particularly relevant, as $P$. knowlesi with its 24 -hour replication cycle can result in a high parasitaemia and severe, life-threatening disease. It is safe to assume that the geographic range of
P. knowlesi comprises all countries in south-east Asia, including the south of China.

Moreover, not only clinicians, but also laboratory personnel, traditionally only trained to identify the four more frequently observed Plasmodium species, $P$. falciparum, $P$. vivax, $P$. ovale and $P$. malariae, should be aware of this infection and its diagnostic challenges. $P$. knowlesi is morphologically very similar to $P$. malariae but can also be confused with P. falciparum in microscopy. As illustrated by the two cases described above, $P$. knowlesi infection causes variable results with commercially available rapid diagnostic tests, which do not seem to be reliable for diagnosis of $P$. knowlesi [3,4]. Although rapid diagnostic tests can complement microscopic diagnosis, they cannot replace microscopy, especially in patients with low parasite loads. For patients suspected of $P$. knowlesi infection, confirmation can be obtained either by specific PCR or by sequence analysis of generic Plasmodium $P C R$ products, which are available in most specialised centres in Europe. While such confirmation is in progress, treatment should be installed based on positive blood smear results. From literature and our experience, it seems that oral treatment regimens suited for uncomplicated $P$. malariae and P. falciparum are also effective in clearing mild $P$. knowlesi infections, since resistance to antimalarial drugs has not been observed yet [5]. For more severe and complicated $P$. knowlesi infections, parenteral treatments associated with short parasite clearance times, such as artesunate, seem preferable.

\section{References}

1. Orth $\mathrm{H}$, Jensen BO, Holtfreter MC, Kocheril SJ, Mallach S, MacKenzie C, et al. Plasmodium knowlesi infection imported to Germany, January 2013. Euro Surveill. 2013;18: (40): pii=20603. Available from: http://www.eurosurveillance.org/ViewArticle. aspx?Articleld $=20603$

PMid:24128698

2. van Hellemond JJ, Rutten M, Koelewijn R, Zeeman AM, Verweij JJ, Wismans PJ, et al. Human Plasmodium knowlesi infection detected by rapid diagnostic tests for malaria. Emerg 
Infect Dis. 2009;15(9):1478-80. http://dx.doi.org/10.3201/

eid1509.090358

PMid:19788819. PMCid:PMC2819855.

3. Link L, Bart A, Verhaar N, van Gool T, Pronk M, Scharnhorst

V. Molecular detection of Plasmodium knowlesi in a Dutch

traveler by real-time PCR. J Clin Microbiol. 2012;50(7):2523-4.

http://dx.doi.org/10.1128/JCM.06859-11

PMid:22573596. PMCid:PMC3405625.

4. Barber BE, William T, Grigg MJ, Piera K, Yeo TW, Anstey NM.

Evaluation of the sensitivity of a pLDH-based and an aldolase-

based rapid diagnostic test for diagnosis of uncomplicated

and severe malaria caused by PCR-confirmed Plasmodium

knowlesi, Plasmodium falciparum, and Plasmodium vivax. J

Clin Microbiol. 2013;51(4):1118-23. http://dx.doi.org/10.1128/

JCM.03285-12

PMid:23345297. PMCid:PMC3666806

5. Kantele A, Jokiranta TS. Review of cases with the emerging

fifth human malaria parasite, Plasmodium knowlesi. Clin Infect

Dis. 2011;52(11):1356-62. http://dx.doi.org/10.1093/cid/cir180

PMid:21596677 